http://jmscr.igmpublication.org/home/

ISSN (e)-2347-176x ISSN (p) 2455-0450

crossref DOI: https://dx.doi.org/10.18535/jmscr/v9i8.01

Journal Of Medical Science And Clinical Research

\title{
Multifocal gastrointestinal stromal tumour and presacral ganglioneuroma in a patient with Von Recklinghausen disease
}

\author{
Authors \\ Jaseela TK $^{1^{*}}$, Deepa $S^{2}$, Sankar $S^{3}$ \\ ${ }^{1,2,3}$ Department of Pathology, Government Medical College Kottayam, Kerala \\ *Corresponding Author \\ Jaseela TK \\ Department of Pathology, Government Medical College Kottayam, Kerala, India
}

\begin{abstract}
Neurofibromatosis 1 is an autosomal dominant genetic disorder and is associated with neuroectodermal tumours arising within multiple organs. Gastrointestinal stromal tumours are seen as a common manifestation of NF 1, but association of ganglioneuromas with neurofibromatosis type 1 is uncommon. Gastrointestinal stromal tumours in NF 1 is commonly located in the small intestine and they can present with gastrointestinal haemorrhage and diagnostic suspicion is essential in these patients to ensure appropriate management. Among the neurofibromatosis type 1 patients only 10-25\% may present with intra-abdominal manifestations, and only 5\% of them are symptomatic and surgery is required only for 2.5\%. We present a case of 39 year old female with NF1 who presented with complaints of recurrent melena and anaemia. At laparotomy multiple GISTs were seen arising from small intestine and a ganglioneuroma arising in the presacral was noted. All these masses were resected along with the neurofibromas present in the midline of anterior abdominal wall. Final diagnosis based on the histopathology was neurofibroma, ganglioneuroma and gastrointestinal stromal tumour. Presacral ganglioneuromas are very rare and only less than 20 cases have been reported so far in literature.

Keywords: Neurofibromatosis 1, Jejunum, Melena, Gastrointestinal Hemorrhage.
\end{abstract}

\section{Case Presentation}

A39 year old female presented with a history of passage of dark coloured stools for past 2 days. She had previous 2 episodes during past 5 years. She had consulted a peripheral hospital then. But she was not investigated properly and was prescribed only hematinics and sent home. Past history revealed that she was a known case of Neurofibromatosis type 1 and her illness started during childhood as she developed multiple swellings and pigmented patches all over the body (table/fig 1). Her mother and youngest daughter also have similar swellings on the skin. On examination the patient had pallor and haemoglobin was $7.2 \mathrm{~g} / \mathrm{dL}$. Multiple cutaneous swellings with size varying from 0.5 to $1 \mathrm{~cm}$ were seen all over the body, they were firm, mobile and non tender. A diffuse swelling of size $2 \times 1 \mathrm{~cm}$, firm in consistency was seen on the dorsum of tongue. Multiple café au-lait spots which was seen as hyper pigmented skin patches with irregular sharp borders also noted. Per abdomen was soft and non tender. 
Spiral CT of abdomen and pelvis showed a well circumscribed small intestinal mass measuring $4.1 \times 3.1 \mathrm{~cm}$ which was predominantly exophytic with homogenous soft tissue density causing mild luminal narrowing (table/fig 2), soft tissue lesion in the pelvis medial to sacrum measuring $3 \times 1.8$ $\mathrm{cm}$ and small hypodense lesion medial to right psoas. Upper gastrointestinal scopy revealed a duodenal polyp with erosion but there was no active bleeding. Colonoscopy done was normal. Their provisional diagnosis was gastrointestinal stromal tumour in small intestine.

Patient underwent laparotomy and a small portion of jejunum with the large polypoidal mass arising from its wall and a small nodular swelling on its serosa was resected. Three swellings arising from the sacral plexus were removed by retroperitoneal approach. Six subcutaneous swellings present in the midline of the anterior abdominal wall also were excised. Post operative period was uneventful. And on follow up after one year patient have no new complaints.

Histopathological examination of the tumours were done. Jejunum showed a well circumscribed neoplasm of size $4 \times 3 \times 3 \mathrm{~cm}$ arising from its wall, and cut section firm, greyish white in colour with mildly lobulated appearance.( Table/Fig 3)On microscopy neoplasm was composed of spindle cells arranged in sheets \& short fascicles. Individual cells had elongated nucleus with fine chromatin and inconspicuous nucleoli. Skenoid fibres seen. Mitotic count was 1 per 50 high power field.( Table/Fig 4)Based on patients history of Neurofibromatosis 1, anatomical location of the tumour and histomorphology gastrointestinal stromal tumour was the most likely histological diagnosis. Other spindle cell tumours like leiomyoma was a close differential diagnosis. Immunohistochemical staining with CD117 showed strong and diffuse cytoplasmic membrane positivity. (Table/Fig 5)Ki 67 index was less than

1\%. (Table/Fig 6)Thus diagnosis of gastrointestinal stromal tumour was confirmed and leiomyoma was excluded. Small nodular mass on surface of jejunum also was GIST. There were three sacral plexus masses out of which two were neurofibroma and remaining one turned out to be a ganglioneuroma. Neurofibromas were of different sizes largest measuring $2 \times 1 \times 1 \mathrm{~cm}$, firm and cut section was tan, glistening. Microscopy showed elongated spindle cells with tapering, wavy buckled nuclei arranged in fascicles and diffusely within a myxoid matrix. (Table/Fig 7)All the anterior abdominal wall swellings excised from midline were confirmed to be neurofibromas. Presacral swelling was a well circumscribed mass measuring $3 \times 2 \times 2 \mathrm{~cm}$, soft to firm consistency, cut section was glistening and grayish white in colour. (Table/Fig 8) Microscopy showed mature ganglion cells scattered in a schwannian stroma. (Table/Fig 9)Thus a diagnosis of ganglioneuroma was made.

After the surgey patient was on regular follow up and no recurrences of GIST was recorded.

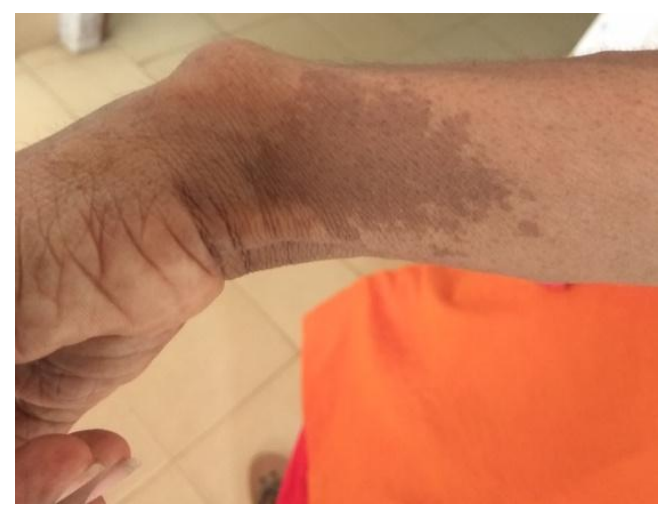

Fig 1: Café au lait spot on lateral aspect of distal forearm.

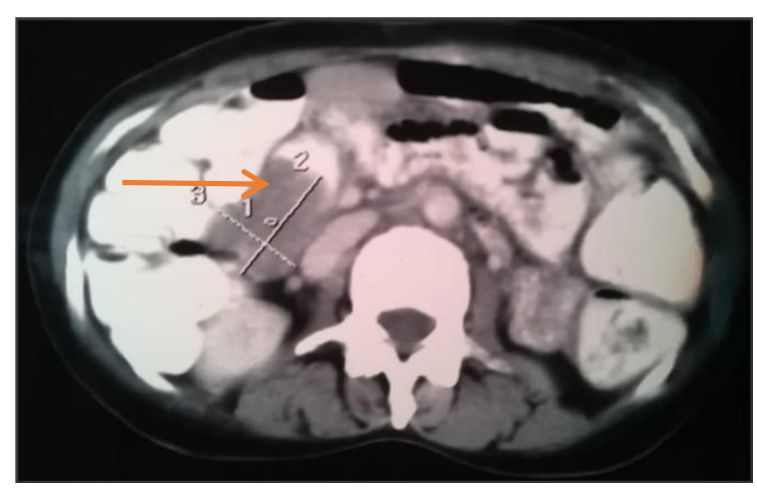

Fig 2. Spiral CT: A well circumscribed predominantly exophytic lesion with homogenous soft tissue density in small intestine causing mild luminal narrowing. 


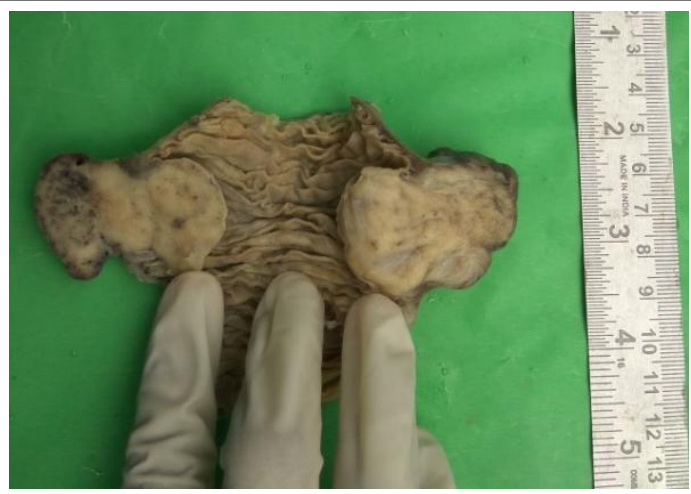

Fig 3. Jejunal GIST: Well circumscribed neoplasm arising from the wall of jejunum, firm in consistency, cut section show greyish white colour and mildly lobulated appearance.

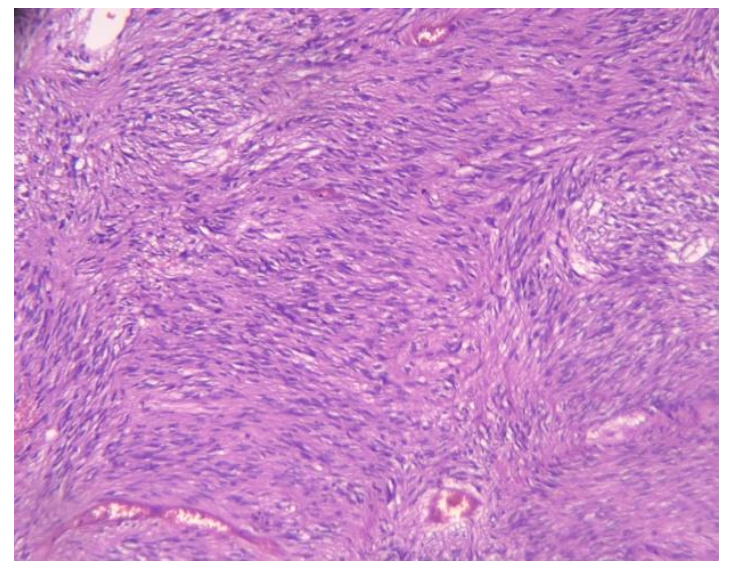

Fig 4. GIST (H\&E stain) (100 X) Neoplasm composed of cells arranged in sheets and short fascicles. Individual cells are spindly with ovoid to elongated nucleus with fine chromatin and inconspicuous nucleoli.

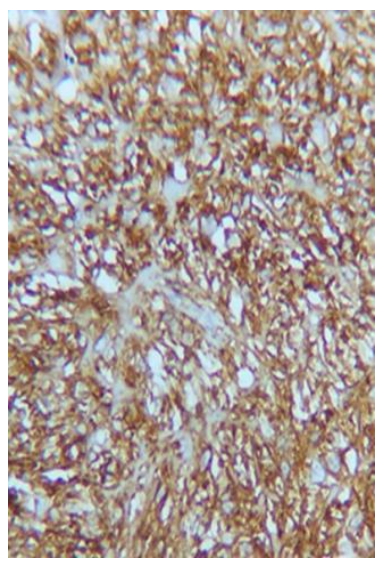

Fig 5 (100X) IHC staining in GIST - CD 117 show strong cytoplasmic membrane positivity

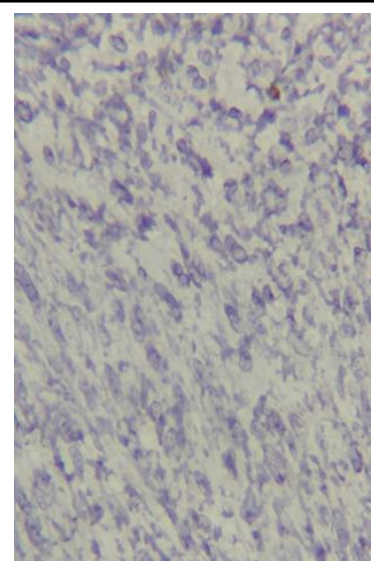

Fig 6 (100X) IHC staining in GIST- Ki 67 index was low in GIST. It was $<1 \%$

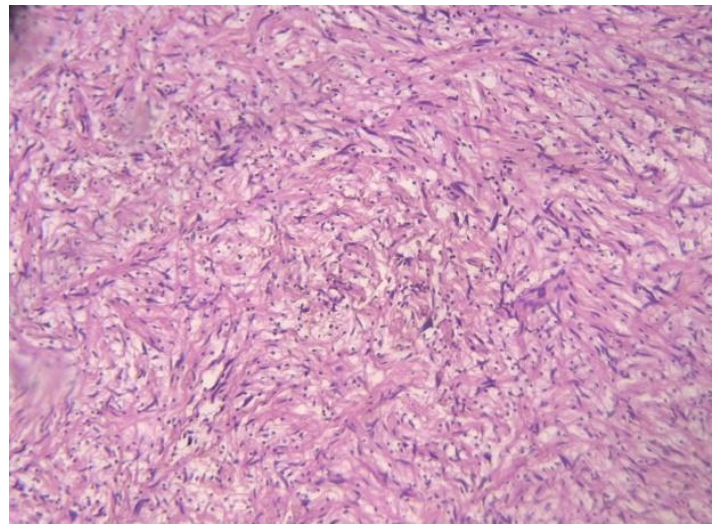

Fig 7. Neurofibromas (H\&E stain) (100X) Elongated spindle cells with tapering, wavy buckled nuclei arranged in fascicles and diffusely.

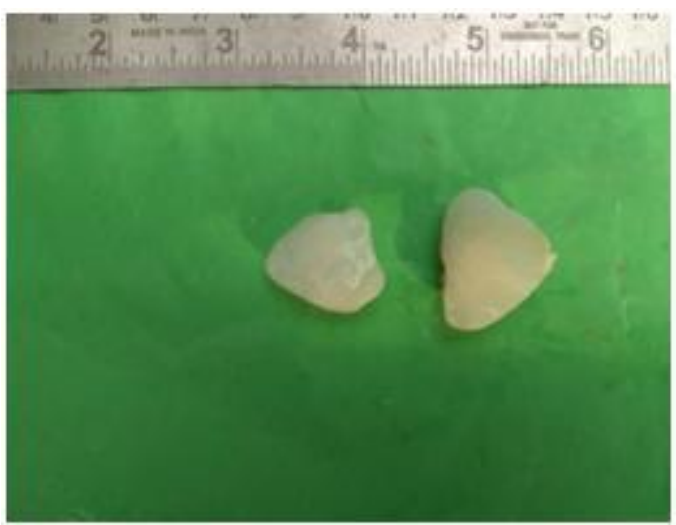

Fig 8. Presacral ganglioneuroma: well circumscribed neoplasm measuring $3 \times 2 \times 2 \mathrm{~cm}$, soft to firm consistency, cut section glistening and white in colour 


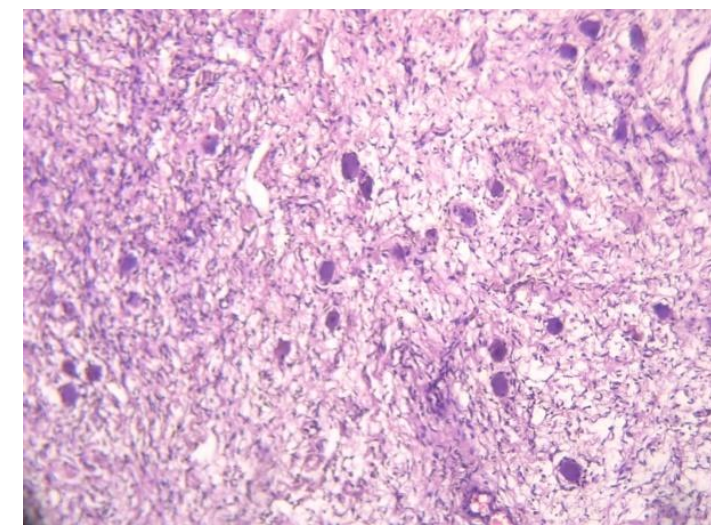

Fig 9. Ganglioneuroma (H\&E stain)(100 X): Diffusely arranged spindly cells with wavy tapering nucleus and mature ganglion cells.

\section{Discussion}

Neurofibromatosis type 1 is a common autosomal dominant syndrome with an incidence of 1 in $3000-4000$ individuals ${ }^{[1]}$. Neurofibromatosis is also known as von Recklinghausen disease owing to classic description of this disease by a German Pathologist Friedrich Daniel von Recklinghausen. ${ }^{[2]}$

A variety of benign and malignant tumours are associated with NF1 and all develop from neural crest derived cells ${ }^{[1]}$. Symptoms manifest differently in each patient because of its highly variable phenotype. Diagnosis of NF1 is done based on clinical criteria established at National Institute of Health Consensus Development Conference. ${ }^{[3]}$ Genetic testing is difficult in NF because of the large size of gene and lot of mutations and the fact that a negative test does not rule out the syndrome. ${ }^{[4]} \mathrm{NF} 1$ gene responsible for the disease is located on the long arm of chromosome 17 and is a tumour suppressor gene that codes for a cytoplasmic protein called neurofibromin. Neurofibromin contains a RAS specific GTPase activating protein (GAP)-related domain which helps in keeping the RAS in its inactive form and thus decreasing mitogenic signalling in the cell. A lack of neurofibromin will result in the continuous activation of RAS signalling pathway and thus unregulated cell growth. This protein is predominantly expressed in neurons, schwann cells, oligodendrocytes, and astrocytes.
Gastrointestinal manifestations of NF-1 vary from microscopic proliferative lesions of autonomic nerves and interstitial cells of Cajal to large masses of Gastrointestinal stromal tumours and neurofibromas. Lesions can appear anywhere in GIT starting from oesophagus to anus. ${ }^{[5]}$ Usual symptoms are abdominal pain and gastrointestinal bleeding, which can be associated with anaemia. Symptoms due to tumour mass as such, like obstruction and jaundice also can occur ${ }^{[6]}$. Among the neurofibromatosis type 1 patients only $10-25 \%$ may present with intra-abdominal manifestations, and only $5 \%$ of them are symptomatic and surgery is required only for $2.5 \% .{ }^{[7]}$ Neurofibromas usually arising in small intestine and retroperitoneum was thought to be the most frequent GI manifestation but now GISTs are being increasingly reported in NF-1 patients.

Gastrointestinal stromal tumours are mesenchymal tumours of the gastrointestinal tract .NF-1 patients have a $6 \%$ risk of developing gastrointestinal stromal tumour during their lifetime. ${ }^{[8]}$ There are dissimilarity in the clinicopathologic characteristics of NF-1 associated GISTs and sporadic GISTs. GIST develop at a younger age in NF-1 patients and usually occur in small intestine $^{[4,9]}$. They are multifocal, mostly benign, with low mitotic activity, spindle cell morphology and are usually positive for the CD117 antigen. Whereas sporadic GIST are more common in stomach than in small intestine, usually occur in an older age group (median 55-65 years) and multiple tumours are $\operatorname{rare}^{[4,8]}$. Histological appearance can be spindle, epithelioid or mixed. Prognosis is better for NF-1 associated GISTs when compared to sporadic GISTs of same size and stage ${ }^{[8]}$. In our case patient presented to the OPD with a complaint of melena, she was anaemic and a jejunal GIST was found to be the culprit. Sporadic GIST harbour a gain of function mutation in KIT (80-85\%) or in some cases an activating mutation of PDGFRA (Platelet Derived Growth Factor Receptor A). NF-1 associated GISTs do not have KIT (receptor tyrosine kinase) or PDGFRA mutations; instead there is mutation 
of NF1 which leads to MAPK (Mitogen Activated Protein Kinases) signal activation ${ }^{[10]}$. Mitotic recombination also has been postulated as an alternative pathogenesis for NF-1 associated GIST $^{[6]}$.

Ganglioneuromas are rare benign tumours in the neuroblastoma group and arise from sympathetic ganglion cells with a prevalence of one per million population $^{[11]}$. In patients with NF-1 frequency of ganglioneuroma is higher. They are commonly located in posterior mediastinum followed by retroperitoneum then cervical region and adrenal gland. Presacral location is very rare and only less than 20 cases have been reported so far in literature. ${ }^{[12,13,14]}$ Most ganglioneuromas are found incidentally owing to its slow growth, absence of distinct clinical features and lack of characteristic radiological features. Because of the benign nature of ganglioneuroma only surgical resection is needed $^{[12,15]}$. In our patients acral plexus swellings were clinically thought to be neurofibromas and after histopathological study only did we discover one of the swelling as ganglioneuroma.

\section{Conclusion}

NF 1 is a common autosomal dominant syndrome with a variety of associated benign \& malignant tumours having neural crest origin. However gastrointestinal manifestations of this disease are often overlooked. The knowledge of common tumours developing in neurofibromatosis and its clinical presentation will definitely benefit in patient management. Although ganglioneuroma is common in NF 1 patients its presacral location is very rare.

\section{References}

1. Laycock-van Spyk S, Thomas N, Cooper DN, Upadhyaya M. Neurofibromatosis type1- associated tumours; their somatic mutational spectrum and pathogenesis. Hum Genomics 2011;5:623-90.

2. Dimitrova V, Yordanova I, Pavlova V, Valtchev V, Gospodinov D, Parashkevova
B,et al. A case of neurofibromatosis type 1. Journal of IMAB. 2008;14:63-67.

3. Miettinen M, Fetsch JF, Sobin LH et al. Gastrointestinal stromal tumours in patients with neurofibromatosis 1: a clinicopathologic and molecular genetic study of 45 cases. AmJ SurgPathol. 2006;30:90-96.

4. Charles J, Tomajian S, Kaye AJ, Russo S, Abadie JV, Kaye AD. Perioperative management of neurofibromatosis type 1.Ochsner J. 2012;12(2):111-121.

5. Agaimy A, Vassos N, Roland S Croner. Gastrointestinal manifestations of neurofibromatosis type 1 (Recklinghausen disease): clinicopathological spectrum with pathogenic considerations. Int $\mathrm{J}$ ClinExp Path. 2012;5(9):852-862.

6. Sanchez- Hidalgo JM, Duran-Martinez M, Molero-Payan R,Rufian-Pena S, ArjonaSanchez A, Casado- Adam A, et al. Gastrointestinal stromal tumours: a multidisciplinary challenge. World J Gastroenterol. 2018;24(18):1925-1941.

7. De la Fuente N, Rodriguez Blanco M, Cerdan G, Artigas V. Acute gastrointestinal bleeding, multiple GIST and Intestinal ganglioneuromatosis in a patient with neurofibromatosis. Cir Esp. 2019;97(4):237-239.

8. Brems H, Beert E, de Ravel T, Legius E.Mechanisms in the pathogenesis of malignant tumours of neurofibromatosis type 1. Lancet oncol. 2009;10(5):508-515.

9. H. Brems, E Legius. Neurofibromatosis type 1.Fletcher DM, Bridge JA, Hogendoorn CW, Mertens $\mathrm{F}$ ed.WHO classification of tumours of soft tissue and bone. 4th edition.Lyon. 2013.286-287.

10. Niinuma M, Suzuki H, Sugai T. Molecular characterization and pathogenesis of gastrointestinal stromal tumour. Transl Gastroenterol Hepatol. 2018;3:2.

11. Dabrowska-Thing A, Rogowski W, Pacho R, Nawrocka-Laskus E, Nitek Z. 
Retroperitoneal ganglioneuroma mimicking a kidney tumour. Case report. Pol J Radiol. 2017;82:283-286.

12. Cerullo G, Marrelli D, Rampone B, Miracco C, Caruso S, Di Martino M, et al. Presacral ganglioneuroma: A case report and review of literature. World $\mathrm{J}$ Gastroenterol. 2007;13(14):2129-31.

13. Lee D, Choe WJ, Lim SD. Ganglioneuroma of the sacrum. Korean J Spine. 2017;14(3):106-108.

14. Kirchweger P, Wundsam H, Fischer I, et al. Total resection of a giant retroperitoneal and mediastinal ganglioneuroma -case report and systematic review of the literature. World J Surg Oncol.2020;18(1).

15. Paasch C, Harder A, Gatzky EJ, Ghadamghai E, Spuler A, Siegel R. Rretroperitoneal paravertebral ganglioneuroma: a multidisciplinary approach facilitates less radical surgery. World J Surg Oncol. 2016;14(1):194. 